Editorial

\title{
Introducing Life Cycle, an open access journal brightening medical science and practice
}

\section{Dong Keon Yon}

Depratment of Pediatrics, Seoul National University College of Medicine, Seoul, South Korea

Received date: Dec 3, 2021. Accepted date: Dec 13, 2021. Published date: Dec 15, 2021.

\section{*Correspondence:}

Dong Keon Yon

Tel: +82-2-6935-2476

E-mail: yonkkang@gmail.com

\section{ORCID}

Dong Keon Yon

https://orcid.org/0000-0003-1628-9948

Copyright () 2021 Life Cycle. This is an Open-Access article distributed under the terms of the Creative Commons Attribution NonCommercial License which permits unrestricted non-commercial use, distribution, and reproduction in any medium, provided the original work is properly cited (CC-BY-NC).
The launch of Life Cycle is an exciting event for the medical and scientific community. Life Cycle is an international, peer-reviewed, and open access general medical journal inviting submissions of any original contribution which broadens, makes advance, or brightens medical science or practice, or those which educates or delights the Journal's readers. Built on the foundation that Life Cycle is the best science journal for medical health research, the Journal is committed to publishing high-quality and cutting-edge Original Research Articles, State-of-theArt Reviews, and Letters that contribute to the advancement of healthy life from birth to senescence.

The broad research remit aims to encompass all medical disciplinary research regarding any stage of life, including epidemiological and societal research, meta-analysis study, clinical trials, and clinical guidelines. The Journal will also publish clinical and policy research that aim to shape and contextualize the debate on this fast-growing discipline. To increase our international reach, we will fully serve as an open access online journal which provides a flexible publication format immediately available after acceptance.

For the purpose to rapidly increase the visibility of our research publications provided to the medical and scientific community, our next objective is to be formally indexed by PubMed Central, PubMed, and Scopus. Although this step is intended to obtain an official Impact Factor, the goal of our mission is establishing both a destination for cutting-edge publication and a platform making advance on the global impact of research. The Life Cycle team shall put our best efforts so that your mesmerizing work will be highly visible to a global network of medical researchers, clinicians, policy makers, industry professionals, patients, and the wider public.

I am grateful and honored to serve as inaugural Editor-in-Chief of Life Cycle. Furthermore, I am also honored for the opportunity to work in collaboration with Dr Youn Ho Shin, who, as Deputy Editor, shall provide breadth and depth, experience, and perspective on directing Life Cycle. On our path approaching the international network, we plan to expand and convene our Editorial Board. The launch of Life Cycle is an exciting event. The flights of publishing medical cutting-edge research have arrived, and Life Cycle is now ready for boarding. We hope that our readers will enjoy and benefit from Life Cycle. 


\section{Author contribution}

Dr DKY contributed to the preparation of this commentary.

\section{Funding}

The authors have not declared a specific grant for this research from any funding agency in the public, commercial or not-for-profit sectors.

\section{Competing interests}

The author has no conflicts of interest to declare for this study.

\section{Provenance and peer review}

Commissioned; internally peer reviewed. 